\title{
Peningkatan Keterampilan Tendangan Dalam Pencak Silat Melalui Variasi Gerak Dasar Tendangan "T" dan Tendangan Depan Pada Siswa Kelas V SDN Pinggir Papas 1
}

\author{
Yoni Sakti Amroin ${ }^{1}$, Nanik Indahwati ${ }^{2}$ \\ Pendidikan Olahraga, Universitas Negeri Surabaya \\ Email:yoniamroin@gmail.com ${ }^{l}$,nanikindahwati@unesa.ac.id ${ }^{2}$
}

\begin{tabular}{l}
\hline \hline Article Info \\
Article history: \\
Article Accepted: May 192021 \\
Publication : July 052021
\end{tabular}

Keywords:

Basic motion, Martial Art, Kick

\begin{abstract}
The purpose of this study was to improve the learning outcomes of basic kick motion skills in pencak silat through variations of the basic ' $T$ ' and front kick motion using assistive media in fifth grade students of SDN Pinggir Papas I in the 2020/2021 academic year. This research was a Classroom Action Research (PTK). The research was carried out using one cycle, if the desired results have not been achieved then the following cycle is continued, with each cycle consisting of planning, implementing actions, observing and reflecting. The subjects of this study were twenty-four students of grade five SDN Pinggir Papas I for the 2020/2021 academic year. The data sources came from teachers and students. Data collection by front kick pencak silat and activity observation during the teaching and learning activities of kicks in pencak silat using learning aids. The data in this study were in the form of quantitative and qualitative data. In this research, it produces data on the improvement of students in learning the basic movements of the T kick and front of the pencak silat with variations and learning aids. The achievement of completeness of the learning outcomes of the pencak silat $T$ kick from pre-cycle one is about sixty-seven percent. From cycle one to cycle two amounted to twenty five percent. Meanwhile, learning outcomes for front kicks from precycle to cycle 1 experienced an increase of fifty-four percent. The improvement of learning outcomes for $T$ and forwards kicks with variations in $T$ and forwards kick exercises has increased until it reaches the learning target, namely reaching the good and very good categories. Based on the results of the study, the conclusion is: Variations in the basic motion of the ' $T$ ' kick and forwards in learning can improve learning outcomes of the basic movement skills of pencak silat kicks in fifth grade students of SDN Piggir Papas I in the 2020/2021 school year.
\end{abstract}

\section{Abstrak}

Tujuan penelitian ini adalah untuk meningkatkan hasil belajar keterampilan gerak dasar tendangan dalam pencak silat melalui variasi gerak dasar tendangan ' $\mathrm{T}$ ' dan depan menggunaan media alat bantu pada siswa kelas lima SDN Pinggir Papas I tahun pelajaran 2020/2021. Penelitian ini merupakan Penelitian Tindakan Kelas (PTK). Penelitian dilaksakanan menggunakan satu siklus, apabila hasil yang diinginkan belum tercapai maka dilanjutkan siklus berkutnya, dengan tiap siklus terdiri atas perencanaan, pelaksanaan tindakan, observasi dan refleksi. Subjekpenelitian ini adalah siswa kelas lima SDN Pinggir Papas I tahun pelajaran 2020/2021 berjumlah dua puluh empat siswa. Sumber data berasal dari guru dan siswa. pengumpulan data dengan testendangan depan pencak silat dan observasi aktivitas selama kegiatan belajar mengajar tendangan dalam pencak silat dengan menggunakan alat bantu pembelajaran. data dalam penelitian ini berupa data kuantitatif dan kualitatif. Pada penelitian ini menghasilkan suatu data peningkatan siswa dalam mempelajari gerak dasar tendangan $\mathrm{T}$ dan depan pencak silat dengan variasi dan media alat bantu pembelajaran. ketercapaian ketuntasan hasil belajar tendangan $\mathrm{T}$ pencak silat dari pra siklus satu sebsar enam puluh tujuh persen. Dari siklus satu ke siklus dua sebesar dua puluh lima persen. Sedangankan hasil belajar tendangan depan dari prasiklus ke siklus 1 mengelami peningkatan sebesar lima puluh empat persen. Peningkatan hasil belajar tendangan $\mathrm{T}$ dan depan dengan variasi latihan tendangan $\mathrm{T}$ dan depan mengalami peningkatan hingga mencapai target pembelajaran yaitu mencapai kategori baik dan sangan baik. , berdsarkan hasil penelitian diperoleh simpulan: Variasi gerak dasar tendangan ' $\mathrm{T}$ ' dan depan dalam pembelajaran dapat meningkatkan hasil belajar keterampilan gerak dasar tendangan pencak silat pada siswa kelas lima SDN Piggir Papas I tahun pelajaran 2020/2021.

This is an open access article under the Lisensi Creative Commons Atribusi-BerbagiSerupa 4.0 Internasional 


\section{PENDAHULUAN}

Anak usia dini memiliki kemampuan belajar sangat tinggi dikarenakan rasa ingin tau berlebih, terjadikhususnya masa kanak-kanak, dan pada saat itu masa perkembangan anak meningkat dengan pesat. Perkembangan motorik kasar potensial pesat pada anak usia dini hingga jenjang sekolah dasar. Akan tetapi dengan berkembangnya iptek, menciptakan berbagai macam kemudahan yang menyebabkan adanya peningkatan perilaku kurang gerak (sedentary behavior) (Ludyanti, 2019). Anak-anak jaman sekarang dan termasuk anak sekolah dasar memliki hal baru seperti memainkan"game online" play station,menonton film atau internet. DiIndonesia 57,3\% anak Indonesia dikategorikan tdak aktif dan berada didepan TV/komputer/PS/Hp $\geq 2$ jam per hari (Heryudarini et al., 2013).

Dalam proses pembelajaran PJOK terdapat cabang olahraga beladiri pencak silat yang diajarkan kepada siswa mulai dari tingkat sekolah dasar (SD), sekolah menengah pertamaa (SMP), dan sekolah menengah atas (SMA). Tidak hanya itu saja, olimpiade olahraga siswa nasinal (O2SN) pencak silat diselenggarakan mulai siswa SD, SMP, dan SMA dari tingkat kabupaten/kota, Provinsi, hingga tingkat Nasional. Menurut Subagyo, 2012:14 pencak silat adalah seni beladiri asli nusantara yang dipengaruhi oleh nilai-nilai spiritual dan budaya bangsa, guru memiliki peranan penting untuk mentransfer kepada generasi penerus bangsa guna membangun kepribadian dan moral yang baik.

Melihat penting dan perlunya bela diri pencak silat selain untuk melestarikan kebudayaan asli Indonesia dan juga karena adanya kejuaraan O2SN mulai tingkat Kabupaten/Kota, Provinsi hingga Nasional, maka pembelajaran bela diri perlu lebih ditingkatkan dan dikembangkan agar lebih menarik guna mencapai hasil pembejaran yang maksimal. Aplikasi proses KBM PJOK khususnya materi pencak silat di SDN Pinggir Papas 1 dilakukan secara biasa. Yang mana pendidik memberi contoh dan penjelasan gerakan dasar dan setelah itu guru memberikan kode untuk siswa melakukan hal tersebut secara bersamaan sesuai instruksi. Cara mengajar seperti ini membuat kebanyakan siwa-siswi bosan dan jenuh, sehingga tidak melakukan gerakan dengan benar. Tidak hanyaitu bahkan terkadang guru tidak memberikan materi beladiri pencak silat karena kurangnya sarana prasarana dan kurang mendalaminya pengetahuan pendidik terhadap pencak silat. Hal ini berdampak pada hasil pembelajaran yang tidak terpenuhi, siswa tidak dapat melakukan gerakan dengan baik apalagi meningkatkan sehingga dalam evaluasi/penilaian hasilnya tidak tuntas.

\section{METODE PENELITIAN}

Dalam penelitian ini, peneliti menggunakan metode Penelitian Tindakan Kelas (PTK). Digunakan sebagai alat untuk menjawab permasalah yang ingin dipecahkan dalam penelitian. Pada dasarnya alasan peneliti mengunakan metode Penelitian Tindakan Kelas (PTK) karena disesuaikan dengan permasalahan yang akan diteliti. Penulis juga beralasan bahwa metode ini cocok untuk diterapkan dalam penelitian yang akan dilakukan. Adapun manfaat yang dapat diambil dari Penelitian Tindakan Kelas ini adalah perbaikan praktis dimana meliputi masalah yang dialami siswa yang diajar oleh guru sebagai pelaku Penelitian tindakan kelas (PTK).

Rancangan model PTK menurut Kurt Lewin (dalam Subroto T dkk, 2016, hlm. 34) teridiri atas 4 (empat komponen), yaitu: (1) Perencanaan atau planning, (2) Tindakan atau acting, (3) Pengamatan atau observing, (4) Refleksi atau reflecting. Berikut definisi operasional setiap variabel: (1) "Variasi Latihan" adalah latihan yang metode-metode dan materi /isi latihannya tidak selalu sama dalam setiap pertemuannya tapi tetap untuk satu tujuan pengembangan teknik, yang tujuannya agar siswa/peserta latihan tidak jenuh atau boan dan malah tertarik pada latihan yang kita buat karena variasi latihan kita tersebut, (2) Peningkatan keterampilan gerak dasar tendangan pencak silat adalah presentase skor yang diperoleh seorang subyek dalam menampilkan kemampuan menendang dengan menggunakan tendangan $\mathrm{T}$ dan depan pada sasaran dengan variasi latihan menggunakan alat bantu tali dan pacing pad . Dalam penelitian ini menggunakan sampel 24 siswa kelas V SDN Pinggir Papas 1. 


\section{HASIL DAN PEMBAHASAN}

Tabel 1. Data Hasil Penilaian Tes Awal Tendangan T

\begin{tabular}{|c|c|c|c|c|c|c|c|c|c|c|c|c|c|c|c|c|c|}
\hline \multirow{2}{*}{ NO } & \multirow{2}{*}{ NAMA } & \multicolumn{14}{|c|}{ Tendangan $\mathbf{T}$} & \multirow{2}{*}{ Jumlah } & \multirow{2}{*}{ Kategori } \\
\hline & & 1 & 2 & 3 & 4 & 5 & 6 & 7 & 8 & 9 & 10 & 11 & 12 & 13 & 14 & & \\
\hline 1 & LK & 1 & 1 & 1 & 1 & 1 & 1 & 0 & 1 & 0 & 1 & 1 & 0 & 1 & 1 & 11 & B \\
\hline 2 & AWA & 1 & 1 & 0 & 1 & 1 & 0 & 0 & 1 & 0 & 0 & 0 & 0 & 0 & 0 & 5 & $\mathrm{~K}$ \\
\hline 3 & $\mathrm{AR}$ & 1 & 1 & 1 & 1 & 0 & 0 & 0 & 1 & 0 & 0 & 1 & 0 & 0 & 1 & 7 & $\mathrm{~S}$ \\
\hline 4 & AZA & 1 & 1 & 1 & 1 & 0 & 0 & 0 & 1 & 0 & 0 & 0 & 0 & 0 & 1 & 6 & $\mathrm{~S}$ \\
\hline 5 & AFWP & 1 & 0 & 1 & 1 & 1 & 0 & 0 & 1 & 0 & 0 & 0 & 0 & 0 & 0 & 5 & $\mathrm{~K}$ \\
\hline 6 & $\mathrm{AKZ}$ & 1 & 1 & 0 & 1 & 0 & 1 & 0 & 1 & 0 & 1 & 1 & 0 & 1 & 1 & 9 & B \\
\hline 7 & An & 1 & 1 & 1 & 1 & 1 & 1 & 0 & 0 & 0 & 0 & 0 & 0 & 0 & 1 & 7 & $S$ \\
\hline 8 & ADN & 1 & 0 & 1 & 1 & 1 & 0 & 0 & 1 & 0 & 1 & 1 & 0 & 0 & 0 & 7 & $S$ \\
\hline 9 & $\mathrm{ADN}$ & 1 & 1 & 0 & 1 & 1 & 1 & 0 & 0 & 0 & 0 & 0 & 0 & 1 & 1 & 7 & $S$ \\
\hline 10 & AAK & 1 & 1 & 1 & 1 & 1 & 0 & 0 & 1 & 0 & 0 & 1 & 0 & 0 & 0 & 7 & $S$ \\
\hline 11 & BAP & 1 & 1 & 1 & 1 & 1 & 0 & 0 & 1 & 0 & 0 & 0 & 0 & 0 & 1 & 7 & $S$ \\
\hline 12 & DEW & 1 & 1 & 1 & 1 & 1 & 0 & 0 & 0 & 0 & 0 & 1 & 0 & 1 & 0 & 7 & $S$ \\
\hline 13 & DHP & 1 & 0 & 0 & 1 & 1 & 0 & 0 & 0 & 0 & 0 & 0 & 0 & 0 & 1 & 4 & $\mathrm{~K}$ \\
\hline 14 & $\mathrm{Fe}$ & 1 & 1 & 1 & 1 & 1 & 0 & 0 & 1 & 0 & 0 & 1 & 0 & 0 & 0 & 7 & $\mathrm{~S}$ \\
\hline 15 & KK & 1 & 1 & 1 & 1 & 1 & 1 & 0 & 1 & 0 & 0 & 0 & 0 & 0 & 0 & 7 & $\mathrm{~S}$ \\
\hline 16 & MKF & 1 & 1 & 1 & 1 & 0 & 1 & 0 & 1 & 0 & 0 & 0 & 0 & 1 & 0 & 7 & $\mathrm{~S}$ \\
\hline 17 & MI & 1 & 1 & 0 & 1 & 0 & 0 & 0 & 0 & 0 & 0 & 1 & 0 & 0 & 1 & 5 & $\mathrm{~K}$ \\
\hline 18 & ML & 1 & 1 & 1 & 1 & 1 & 1 & 0 & 0 & 0 & 0 & 0 & 0 & 0 & 0 & 6 & $\mathrm{~S}$ \\
\hline 19 & MKI & 1 & 1 & 1 & 1 & 0 & 0 & 0 & 0 & 0 & 0 & 0 & 0 & 1 & 1 & 6 & $S$ \\
\hline 20 & MAMA & 1 & 0 & 0 & 1 & 0 & 0 & 0 & 1 & 0 & 0 & 0 & 0 & 0 & 0 & 3 & $\mathrm{~K}$ \\
\hline 21 & MA & 1 & 1 & 1 & 1 & 1 & 1 & 0 & 0 & 0 & 1 & 1 & 0 & 0 & 0 & 8 & $\mathrm{~S}$ \\
\hline 22 & IND & 1 & 1 & 1 & 1 & 1 & 1 & 0 & 0 & 0 & 0 & 0 & 0 & 1 & 1 & 8 & $\mathrm{~S}$ \\
\hline 23 & RH & 1 & 1 & 1 & 1 & 0 & 0 & 0 & 1 & 0 & 0 & 1 & 0 & 0 & 1 & 7 & $\mathrm{~S}$ \\
\hline 24 & SK & 1 & 1 & 0 & 1 & 0 & 0 & 0 & 1 & 0 & 0 & 1 & 0 & 1 & 1 & 7 & $S$ \\
\hline
\end{tabular}

Berdasarkan tabel diatas menunjukkan bahwa, hasil tes awal gerakan dasar tendangan $\mathrm{T}$ dari 24 siswa adalah: 2 (8\%) siswa kategori baik, 17 (71\%) siswa kategori sedang, dan 5 (21\%) siswa dengan kategori kurang. Berdasarkan data tes awal tersebutmenunjukkan bahwa hanya $8 \%$ siswayang masuk kategori baik.

Tabel 2. Data Hasil Penilaian Siklus I Tendangan T

\begin{tabular}{|c|c|c|c|c|c|c|c|c|c|c|c|c|c|c|c|c|c|}
\hline \multirow{2}{*}{ NO } & \multirow{2}{*}{ NAMA } & \multicolumn{14}{|c|}{ Tendangan $\mathbf{T}$} & \multirow{2}{*}{ Jumlah } & \multirow{2}{*}{ Kategori } \\
\hline & & 1 & 2 & 3 & 4 & 5 & 6 & 7 & 8 & 9 & 10 & 11 & 12 & 13 & 14 & & \\
\hline 1 & LK & 1 & 1 & 1 & 1 & 1 & 1 & 1 & 1 & 0 & 1 & 1 & 0 & 1 & 1 & 12 & SB \\
\hline 2 & AWA & 1 & 1 & 1 & 1 & 1 & 1 & 0 & 1 & 0 & 0 & 0 & 0 & 0 & 1 & 8 & $\mathrm{~S}$ \\
\hline 3 & AR & 1 & 1 & 1 & 1 & 0 & 0 & 0 & 1 & 0 & 1 & 1 & 0 & 0 & 1 & 8 & $\mathrm{~S}$ \\
\hline 4 & AZA & 1 & 1 & 1 & 1 & 0 & 1 & 1 & 1 & 1 & 0 & 0 & 0 & 0 & 1 & 9 & $\mathrm{~B}$ \\
\hline 5 & AFWP & 1 & 1 & 1 & 1 & 1 & 1 & 0 & 1 & 0 & 1 & 0 & 0 & 0 & 1 & 9 & $\mathrm{~B}$ \\
\hline 6 & $\mathrm{AKZ}$ & 1 & 1 & 1 & 1 & 0 & 1 & 1 & 1 & 0 & 1 & 1 & 0 & 1 & 1 & 11 & B \\
\hline 7 & An & 1 & 1 & 1 & 1 & 1 & 1 & 0 & 0 & 0 & 0 & 0 & 0 & 0 & 1 & 7 & $\mathrm{~S}$ \\
\hline 8 & ADN & 1 & 1 & 1 & 1 & 1 & 0 & 0 & 1 & 0 & 1 & 1 & 0 & 0 & 0 & 8 & $S$ \\
\hline 9 & $\mathrm{ADN}$ & 1 & 1 & 1 & 1 & 1 & 1 & 1 & 0 & 0 & 0 & 0 & 0 & 1 & 1 & 9 & B \\
\hline
\end{tabular}




\begin{tabular}{c|c|c|c|c|c|c|c|c|c|c|c|c|c|c|c|c|c}
\hline 10 & AAK & 1 & 1 & 1 & 1 & 1 & 1 & 0 & 1 & 0 & 0 & 1 & 0 & 0 & 1 & 9 & B \\
\hline 11 & BAP & 1 & 1 & 1 & 1 & 1 & 0 & 1 & 1 & 1 & 0 & 0 & 0 & 0 & 1 & 9 & B \\
\hline 12 & DEW & 1 & 1 & 1 & 1 & 1 & 0 & 0 & 0 & 0 & 0 & 1 & 0 & 1 & 0 & 7 & S \\
\hline 13 & DHP & 1 & 1 & 1 & 1 & 1 & 1 & 1 & 0 & 0 & 0 & 0 & 0 & 0 & 1 & 8 & B \\
\hline 14 & Fe & 1 & 1 & 1 & 1 & 1 & 1 & 1 & 1 & 0 & 0 & 1 & 0 & 0 & 0 & 9 & B \\
\hline 15 & KK & 1 & 1 & 1 & 1 & 1 & 1 & 1 & 1 & 0 & 0 & 0 & 0 & 0 & 0 & 8 & B \\
\hline 16 & MKF & 1 & 1 & 1 & 1 & 0 & 1 & 1 & 1 & 0 & 0 & 0 & 0 & 1 & 1 & 9 & B \\
\hline 17 & MI & 1 & 1 & 1 & 1 & 1 & 0 & 1 & 0 & 0 & 1 & 1 & 0 & 0 & 1 & 9 & B \\
\hline 18 & ML & 1 & 1 & 1 & 1 & 1 & 1 & 0 & 0 & 1 & 0 & 0 & 0 & 0 & 0 & 7 & S \\
\hline 19 & MKI & 1 & 1 & 1 & 1 & 0 & 1 & 1 & 0 & 0 & 0 & 0 & 0 & 1 & 1 & 8 & B \\
\hline 20 & MAMA & 1 & 1 & 1 & 1 & 1 & 0 & 1 & 1 & 0 & 1 & 0 & 0 & 0 & 1 & 9 & B \\
\hline 21 & MA & 1 & 1 & 1 & 1 & 1 & 1 & 0 & 0 & 0 & 1 & 1 & 0 & 0 & 0 & 8 & B \\
\hline 22 & IND & 1 & 1 & 1 & 1 & 1 & 1 & 1 & 0 & 0 & 0 & 0 & 0 & 1 & 1 & 9 & B \\
\hline 23 & RH & 1 & 1 & 1 & 1 & 1 & 0 & 0 & 1 & 1 & 0 & 1 & 0 & 0 & 1 & 9 & B \\
\hline 24 & SK & 1 & 1 & 1 & 1 & 1 & 1 & 1 & 1 & 0 & 1 & 1 & 0 & 1 & 1 & 12 & SB \\
\hline
\end{tabular}

Berdasarkan tabel diatas menunjukkan bahwa, hasil tes awal gerakan dasar tendangan $\mathrm{T}$ dari 24 siswa adalah: 2 (8\%) siswa kategori sangat baik, 16 (67\%)siswa kategori baik, dan 6 (25\%) siswa dengan kategori sedang. Berdasarkan data tes siklus 1 tersebut menunjukkan bahwa $67 \%$ siswayang masuk kategori baik, terjadi peningkatan $67 \%$ dari tes awal sehingga siswa yang telah memenuhi indicator keberhasilan mencapai $75 \%$.

Tabel 3. Data Hasil Siklus 2 Tendangan T

\begin{tabular}{c|c|c|c|c|c|c|c|c|c|c|c|c|c|c|c|c|c}
\hline \multirow{2}{*}{ NO } & \multirow{2}{*}{ NAMA } & \multicolumn{10}{|c|}{ Tendangan T } & \multirow{2}{*}{ Jumlah } & \multirow{2}{*}{ Kategori } \\
\hline & 1 & 2 & 3 & 4 & 5 & 6 & 7 & 8 & 9 & 10 & 11 & 12 & 13 & 14 & & \\
\hline 1 & LK & 1 & 1 & 1 & 1 & 1 & 1 & 1 & 1 & 1 & 1 & 1 & 1 & 1 & 1 & 14 & SB \\
\hline 2 & AWA & 1 & 1 & 1 & 1 & 1 & 1 & 0 & 1 & 0 & 1 & 1 & 1 & 1 & 1 & 12 & SB \\
\hline 3 & AR & 1 & 1 & 1 & 1 & 0 & 1 & 0 & 1 & 1 & 1 & 1 & 1 & 0 & 1 & 11 & B \\
\hline 4 & AZA & 1 & 1 & 1 & 1 & 0 & 1 & 1 & 1 & 1 & 0 & 1 & 1 & 1 & 1 & 12 & SB \\
\hline 5 & AFWP & 1 & 1 & 1 & 1 & 1 & 1 & 0 & 1 & 0 & 1 & 1 & 1 & 1 & 1 & 12 & SB \\
\hline 6 & AKZ & 1 & 1 & 1 & 1 & 0 & 1 & 1 & 1 & 1 & 1 & 1 & 1 & 1 & 1 & 13 & SB \\
\hline 7 & An & 1 & 1 & 1 & 1 & 1 & 1 & 0 & 0 & 1 & 1 & 1 & 1 & 1 & 1 & 12 & SB \\
\hline 8 & ADN & 1 & 1 & 1 & 1 & 1 & 0 & 0 & 1 & 1 & 1 & 1 & 0 & 0 & 1 & 10 & B \\
\hline 9 & ADN & 1 & 1 & 1 & 1 & 1 & 1 & 1 & 0 & 0 & 1 & 1 & 1 & 1 & 1 & 12 & SB \\
\hline 10 & AAK & 1 & 1 & 1 & 1 & 1 & 1 & 0 & 1 & 1 & 0 & 1 & 1 & 1 & 1 & 12 & SB \\
\hline 11 & BAP & 1 & 1 & 1 & 1 & 1 & 0 & 1 & 1 & 1 & 0 & 1 & 1 & 0 & 1 & 11 & B \\
\hline 12 & DEW & 1 & 1 & 1 & 1 & 1 & 0 & 0 & 0 & 1 & 1 & 1 & 1 & 1 & 1 & 11 & B \\
\hline 13 & DHP & 1 & 1 & 1 & 1 & 1 & 1 & 1 & 0 & 0 & 1 & 1 & 1 & 1 & 1 & 12 & SB \\
\hline 14 & Fe & 1 & 1 & 1 & 1 & 1 & 1 & 1 & 1 & 0 & 0 & 1 & 1 & 0 & 1 & 11 & B \\
\hline 15 & KK & 1 & 1 & 1 & 1 & 1 & 1 & 1 & 1 & 0 & 1 & 1 & 0 & 0 & 1 & 11 & B \\
\hline 16 & MKF & 1 & 1 & 1 & 1 & 0 & 1 & 1 & 1 & 0 & 1 & 0 & 1 & 1 & 1 & 11 & B \\
\hline 17 & MI & 1 & 1 & 1 & 1 & 1 & 0 & 1 & 0 & 0 & 1 & 1 & 1 & 0 & 1 & 10 & B \\
\hline 18 & ML & 1 & 1 & 1 & 1 & 1 & 1 & 0 & 1 & 1 & 0 & 0 & 1 & 1 & 1 & 11 & B \\
\hline 19 & MKI & 1 & 1 & 1 & 1 & 0 & 1 & 1 & 0 & 0 & 1 & 1 & 1 & 1 & 1 & 11 & B \\
\hline 20 & MAMA & 1 & 1 & 1 & 1 & 1 & 0 & 1 & 1 & 0 & 1 & 1 & 1 & 0 & 1 & 11 & B \\
\hline
\end{tabular}




\begin{tabular}{c|c|c|c|c|c|c|c|c|c|c|c|c|c|c|c|c|c}
\hline 21 & MA & 1 & 1 & 1 & 1 & 1 & 1 & 0 & 1 & 0 & 1 & 1 & 0 & 1 & 1 & 12 & SB \\
\hline 22 & IND & 1 & 1 & 1 & 1 & 1 & 1 & 1 & 0 & 0 & 1 & 1 & 1 & 1 & 1 & 12 & SB \\
\hline 23 & RH & 1 & 1 & 1 & 1 & 1 & 0 & 0 & 1 & 1 & 0 & 1 & 0 & 1 & 1 & 10 & B \\
\hline 24 & SK & 1 & 1 & 1 & 1 & 1 & 1 & 1 & 1 & 0 & 1 & 1 & 1 & 1 & 1 & 13 & SB \\
\hline
\end{tabular}

Berdasarkan tabel diatas menunjukkan bahwa, hasil tes awal gerakan dasar tendangan $\mathrm{T}$ dari 24 siswa adalah:12 (50\%) siswa kategori sangat baik, dan 12 (50\%) siswa kategori baik. Berdasarkan data tes siklus 2 tersebut menunjukkan bahwa semua siswa telah memenuhi target pembelajaran.

Tabel 4. Data Hasil Penilaian Tes Awal Tendangan Depan

\begin{tabular}{|c|c|c|c|c|c|c|c|c|c|c|c|c|c|c|c|c|c|}
\hline \multirow{2}{*}{ NO } & \multirow{2}{*}{ NAMA } & \multicolumn{14}{|c|}{ Tendangan Depan } & \multirow{2}{*}{ Jumlah } & \multirow{2}{*}{ Kategori } \\
\hline & & 1 & 2 & 3 & 4 & 5 & 6 & 7 & 8 & 9 & 10 & 11 & 12 & 13 & 14 & & \\
\hline 1 & LK & 1 & 1 & 1 & 1 & 0 & 1 & 0 & 1 & 0 & 0 & 1 & 0 & 0 & 1 & 8 & $S$ \\
\hline 2 & AWA & 1 & 1 & 1 & 1 & 0 & 1 & 0 & 1 & 1 & 0 & 0 & 0 & 0 & 1 & 8 & $S$ \\
\hline 3 & AR & 1 & 1 & 1 & 1 & 1 & 1 & 0 & 1 & 1 & 0 & 1 & 0 & 0 & 1 & 10 & $\mathrm{~B}$ \\
\hline 4 & AZA & 1 & 1 & 1 & 1 & 0 & 1 & 0 & 0 & 1 & 0 & 1 & 0 & 0 & 1 & 8 & $\mathrm{~S}$ \\
\hline 5 & AFWP & 1 & 1 & 1 & 1 & 1 & 1 & 0 & 0 & 0 & 0 & 1 & 0 & 0 & 1 & 8 & $S$ \\
\hline 6 & $\mathrm{AKZ}$ & 1 & 0 & 0 & 1 & 0 & 1 & 0 & 0 & 1 & 0 & 1 & 0 & 0 & 1 & 6 & $S$ \\
\hline 7 & An & 1 & 1 & 1 & 1 & 0 & 1 & 0 & 1 & 1 & 0 & 1 & 0 & 0 & 1 & 9 & $\mathrm{~B}$ \\
\hline 8 & $\mathrm{ADN}$ & 1 & 1 & 1 & 1 & 0 & 1 & 0 & 1 & 1 & 0 & 1 & 0 & 1 & 1 & 10 & $\mathrm{~B}$ \\
\hline 9 & $\mathrm{ADN}$ & 1 & 1 & 1 & 1 & 1 & 1 & 0 & 1 & 1 & 0 & 0 & 0 & 0 & 1 & 9 & $\mathrm{~B}$ \\
\hline 10 & AAK & 1 & 1 & 1 & 1 & 1 & 1 & 0 & 0 & 0 & 0 & 1 & 0 & 0 & 1 & 8 & $S$ \\
\hline 11 & BAP & 1 & 1 & 1 & 1 & 0 & 1 & 0 & 0 & 1 & 0 & 1 & 0 & 0 & 0 & 7 & $\mathrm{~S}$ \\
\hline 12 & DEW & 1 & 1 & 1 & 1 & 0 & 1 & 0 & 1 & 1 & 0 & 1 & 0 & 0 & 1 & 9 & B \\
\hline 13 & DHP & 1 & 1 & 1 & 1 & 0 & 1 & 0 & 1 & 1 & 0 & 1 & 0 & 1 & 1 & 10 & B \\
\hline 14 & $\mathrm{Fe}$ & 1 & 0 & 0 & 1 & 0 & 1 & 0 & 1 & 1 & 0 & 1 & 0 & 0 & 1 & 7 & $S$ \\
\hline 15 & $\mathrm{KK}$ & 1 & 1 & 1 & 1 & 1 & 1 & 0 & 0 & 1 & 0 & 1 & 0 & 0 & 1 & 9 & $\mathrm{~B}$ \\
\hline 16 & $\mathrm{MKF}$ & 1 & 1 & 1 & 1 & 1 & 1 & 0 & 1 & 0 & 0 & 1 & 0 & 0 & 1 & 9 & $\mathrm{~B}$ \\
\hline 17 & MI & 1 & 1 & 1 & 1 & 0 & 1 & 0 & 0 & 1 & 0 & 1 & 0 & 0 & 1 & 8 & $S$ \\
\hline 18 & ML & 1 & 1 & 1 & 1 & 0 & 1 & 0 & 1 & 0 & 0 & 0 & 0 & 0 & 1 & 7 & $S$ \\
\hline 19 & MKI & 1 & 1 & 1 & 1 & 1 & 1 & 0 & 0 & 0 & 0 & 1 & 0 & 0 & 1 & 8 & $\mathrm{~S}$ \\
\hline 20 & MAMA & 1 & 1 & 1 & 1 & 1 & 1 & 0 & 1 & 1 & 0 & 1 & 0 & 0 & 1 & 10 & B \\
\hline 21 & MA & 1 & 1 & 1 & 1 & 0 & 1 & 0 & 1 & 1 & 0 & 1 & 0 & 0 & 1 & 9 & B \\
\hline 22 & IND & 1 & 1 & 1 & 1 & 0 & 1 & 0 & 1 & 1 & 0 & 1 & 0 & 0 & 1 & 9 & $\mathrm{~B}$ \\
\hline 23 & $\mathrm{RH}$ & 1 & 1 & 1 & 1 & 0 & 1 & 0 & 0 & 1 & 0 & 1 & 0 & 0 & 1 & 8 & $\mathrm{~S}$ \\
\hline 24 & SK & 1 & 0 & 0 & 1 & 0 & 1 & 0 & 1 & 1 & 0 & 1 & 0 & 0 & 1 & 7 & $\mathrm{~S}$ \\
\hline
\end{tabular}

Berdasarkan tabel diatas menunjukkan bahwa, hasil tes awal gerakan dasar tendangan depan dari 24 siswa adalah: 11(46\%) siswa kategori baik, 13 (54\%) siswa kategori sedang. Berdasarkan data tes awal tersebut menunjukkan bahwa terdapat 54\% siswa yang belum memenuhi target pembelajaran. 
Tabel 5. Data Hasil Penilaian Siklus I Tendangan Depan

\begin{tabular}{c|c|c|c|c|c|c|c|c|c|c|c|c|c|c|c|c|c}
\hline \multirow{2}{*}{ NO } & \multirow{2}{*}{ NAMA } & \multicolumn{10}{|c|}{ Tendangan Depan } & \multirow{2}{*}{ Jumlah } & Kategori \\
\hline & 1 & 2 & 3 & 4 & 5 & 6 & 7 & 8 & 9 & 10 & 11 & 12 & 13 & 14 & & \\
\hline 1 & LK & 1 & 1 & 1 & 1 & 1 & 1 & 1 & 1 & 1 & 1 & 1 & 0 & 0 & 1 & 12 & SB \\
\hline 2 & AWA & 1 & 1 & 1 & 1 & 0 & 1 & 1 & 1 & 1 & 0 & 1 & 0 & 1 & 1 & 10 & B \\
\hline 3 & AR & 1 & 1 & 1 & 1 & 1 & 1 & 1 & 1 & 1 & 0 & 1 & 0 & 0 & 1 & 11 & B \\
\hline 4 & AZA & 1 & 1 & 1 & 1 & 0 & 1 & 1 & 0 & 1 & 0 & 1 & 0 & 1 & 1 & 10 & B \\
\hline 5 & AFWP & 1 & 1 & 1 & 1 & 1 & 1 & 1 & 0 & 0 & 0 & 1 & 0 & 1 & 1 & 10 & B \\
\hline 6 & AKZ & 1 & 1 & 1 & 1 & 0 & 1 & 1 & 0 & 1 & 0 & 1 & 0 & 1 & 1 & 10 & B \\
\hline 7 & An & 1 & 1 & 1 & 1 & 0 & 1 & 1 & 1 & 1 & 0 & 1 & 0 & 0 & 1 & 11 & B \\
\hline 8 & ADN & 1 & 1 & 1 & 1 & 0 & 1 & 1 & 1 & 1 & 0 & 1 & 0 & 1 & 1 & 11 & B \\
\hline 9 & ADN & 1 & 1 & 1 & 1 & 1 & 1 & 1 & 1 & 1 & 0 & 0 & 0 & 1 & 1 & 11 & B \\
\hline 10 & AAK & 1 & 1 & 1 & 1 & 1 & 1 & 1 & 0 & 1 & 0 & 1 & 0 & 1 & 1 & 10 & B \\
\hline 11 & BAP & 1 & 1 & 1 & 1 & 0 & 1 & 1 & 0 & 1 & 0 & 1 & 0 & 1 & 0 & 9 & B \\
\hline 12 & DEW & 1 & 1 & 1 & 1 & 0 & 1 & 0 & 1 & 1 & 0 & 1 & 0 & 1 & 1 & 10 & B \\
\hline 13 & DHP & 1 & 1 & 1 & 1 & 0 & 1 & 1 & 1 & 1 & 0 & 1 & 0 & 1 & 1 & 11 & B \\
\hline 14 & Fe & 1 & 0 & 0 & 1 & 0 & 1 & 1 & 1 & 1 & 0 & 1 & 0 & 1 & 1 & 9 & B \\
\hline 15 & KK & 1 & 1 & 1 & 1 & 1 & 1 & 1 & 0 & 1 & 0 & 1 & 0 & 1 & 1 & 11 & B \\
\hline 16 & MKF & 1 & 1 & 1 & 1 & 1 & 1 & 1 & 1 & 0 & 0 & 1 & 0 & 1 & 1 & 11 & B \\
\hline 17 & MI & 1 & 1 & 1 & 1 & 0 & 1 & 1 & 1 & 1 & 0 & 1 & 0 & 1 & 1 & 10 & B \\
\hline 18 & ML & 1 & 1 & 1 & 1 & 0 & 1 & 1 & 1 & 0 & 0 & 0 & 0 & 1 & 1 & 9 & B \\
\hline 19 & MKI & 1 & 1 & 1 & 1 & 1 & 1 & 1 & 0 & 0 & 0 & 1 & 0 & 1 & 1 & 10 & B \\
\hline 20 & MAMA & 1 & 1 & 1 & 1 & 1 & 1 & 1 & 1 & 1 & 0 & 1 & 0 & 0 & 1 & 11 & B \\
\hline 21 & MA & 1 & 1 & 1 & 1 & 0 & 1 & 1 & 1 & 1 & 0 & 1 & 0 & 1 & 1 & 11 & B \\
\hline 22 & IND & 1 & 1 & 1 & 1 & 0 & 1 & 1 & 1 & 1 & 0 & 1 & 0 & 0 & 1 & 10 & B \\
\hline 23 & RH & 1 & 1 & 1 & 1 & 0 & 1 & 1 & 0 & 1 & 0 & 1 & 0 & 0 & 1 & 9 & B \\
\hline 24 & SK & 1 & 1 & 1 & 1 & 0 & 1 & 1 & 1 & 1 & 0 & 1 & 0 & 0 & 1 & 10 & B \\
\hline
\end{tabular}

Berdasarkan tabel diatas menunjukkan bahwa, hasil tes awal gerakan dasar tendangan depan dari 24 siswa adalah: 1 (4\%) siswa kategori sangat baik, 23 (96\%) siswa kategori baik. Berdasarkan data tes awal tersebut menunjukkan bahwa seluruh siswa telah mengalami peningkatan dan memenuhi target prmbelajaran.

\section{PEMBAHASAN}

Menurut Harsono (2017: 50) mengatakan bahwa "Traning adalah proses yang sitematis dari berlatih/bekerja, yang di lakukan secara berulang-ulang dengan kian hari kian menambah jumlah beban latihan atau pekerjaannya". Variasi latihan adalah latihan yang metode-metode dan materi/isi latihannya tidak selalu sama di setiap pertemuannya tapi tetap untuk satu tujuan pengembangan teknik dan tujuannya agar atlit tidak jenuh pada saat latihan. Menurut Harsono (2015:76) "Latihan yang dilaksanakan dengan betul biasanya menuntut banyak waktu dan tenaga dari atlet".Selanjutnya Harsono (2015:78) "Untuk mencegah kebosanan berlatih ini, pelatih harus kreatif dan pandai mencari dan menerapkan variasi-variasi dalam latihan".

Variasi latihan didefinisikan sebagai metode dimana setiap isi latihan tidak sama tetapi tetap untuk satu tujuan pengembangan teknik, yang tujuannya agar anak latih tidak jenuh atau bosan dan tertarik pada latihan yang dibuat karena latihan yang lebih bervariasi (Sandhi dan Budiwanto, 2016: 37). Sandhi dan Budiwanto (2016: 27) juga mengutarakan "Prinsip variasi latihan yang pernah dikuasai dan diberikan kepada atlet kurang bervariasi membuat atlet bosan 
dengan latihan yang diulang-ulang. Hal demikian yang membuat atlet tidak mendapatkan hasil yang optimal. Dari sini seorang pelatih dituntut untuk menciptakan metode dan model latihan yang bervariasi dalam mengatasi kejenuhan atlet.

Berdasarkan data peningkatan hasil belajar gerak dasar pencak silat menggunakan variasi latihan tendangan "T" dan tendangan depan pada siswa kelas V SDN Pinggir Papas 1 tahun pelajaran 2020/2021 pada prasiklus, setelah siklus 1 dan setelah siklus 2 menunjukkan bahwa, pembelajaran gerak dasar pencak silat menggunakan variasi latihan tendangan " $T$ " dan tendangan depan menggunakan alat bantu dapat meningkatkan hasil belajar gerak dasar pencak silat. Hal ini karenakan adanya variasi latihan yang berbeda namun tetap pada satu tujuan yang sama yaitusiswa memahami lebih kongkrit materi pelajaran yang diterimanya, melakukan gerak dasar yang harus dikenakan pada bantalan dan melewati tali. Dengan adanya alat bantu bantalan dan tali, siswa lebih semangat melakukan gerak dasar pencak silat secara berulang-ulang. Pembelajaran gerak dasar pencak silat dengan variasi tendangan " $T$ " dan Tendangan depan dengan adanya sasaran yang dilakukan secara berulang-ulang menjadikan proses pembelajaran menyenangkan serta tidak menoton dan menjadikan siswa belajar dengan maksimal hingga mendapatkan hasil yang optimal.

\section{KESIMPULAN}

Setelah penelitian dilaksanakan mengenai "Peningkatan Keterampilan gerak dasar dalam pencak silat melalui variasi gerak dasar tendangan " $T$ " dan tendangan depan dalam pencak silat. Peneliti mendapatkan beberapa kesimpulan sebagai berikut :

1. Dengan penerapan variasi gerak dasar tendangan "T" dan tendangan depanterhadap keterampilan gerak dasar tendangan pencak silat terjadipeningkatan dalam setiap siklusnya, hingga dapat mencapai target pembelajarandisekolah SDN Pinggir Papaps 1.

2. Variasi latihan tendangan $\mathrm{T}$ dan depan memberi pengaruh yang banyak dalam meningkatkan keterampilan gerak dasar tendangan $\mathrm{T}$ dan depan sehingga berhasil mencapai taget pembelajaran.

\section{SARAN}

Melalui data-data yang diperoleh dari penggunaan variasi gerak dasar tendangan " $T$ " dan tendangan depan terhadap keterampilan gerak dasar tendangan pencak silat, penulis mengajukan saran-saranyang diharapkan akan memberikan manfaat bagi pihak yang terkait.Adapun saransaran tersebut adalah sebagai berikut:

1. Bagi para guruPJOK diharapkan memberikan model pengajaranyang lebih meluas dan mampu memberikan cara pengajaran yang menyenangkan dan bisamenarik semangat siswa.

2. Bagi para guruPJOK diharapkan dalam proses mengajarmemberikan materi pembelajaran yang lebih menekankan ke arahpermainanyang sifatnya menyenangkan tetapi tetap memfokuskan tujuan pembelajaran,supaya siswa lebih antusias.

3. Bagi para siswa agar lebih mengembangkan pemahaman dalammelakukan keterampilan gerakan pencak silat supaya hasil pembelajaran dapatlebih meningkat lagi.

\section{DAFTAR PUSTAKA}

Aqib, Z., Maftuh, M., \& Kawentar. (2009). Penelitian Tindakan Kelas Untuk Guru, SMP, $S M A, S M K$. Bandung: CV. Yrama Widya.

Badan Standar Nasional Pendidikan. 2006. Lampiran Standar Isi PJOK dan Kesehatan. Jakarta.

Burhein, Erick. (2007). Aktivitas Fisik Olahraga untuk Pertumbuhan dan Perkembangan Siswa SD. Indonesian Journal of Primary Education, 1(1):51-58

Depdiknas.(2008). Kamus besar bahasa Indonesia.Jakarta: Balai Pustaka

Desmita. 2007. Psikologi Perkembangan. Bandung: PT Remaja Rosdakarya.

Elizabeth Hurlock. (2008). Perkembangan Anak. Jilid 2. Terjemahan:Meitasari Tjandrasa. Jakarta: Gramedia 
Hamdani.2014. Evaluasi IMT \& Kondisi Atlet PELATNAS Pencak Silat SEA Games Tahun 2013.Tesis tidak diterbitkan.Surabaya : PPsUniversitas Negeri Surabaya.

Hariyadi, R. Kotot Slamet. (2003). Teknik Dasar Pencak Silat Tanding. Jakarta: Dian Rakyat.

Heryudarini, T. et al.. 2013. Pola Aktivitas Fisik Anak Usia 6-12 tahun. Gizi Indonesia, 36(2):99-108

Johansyah Lubis. 2004. Pencak Silat Panduan Praktis. Jakarta: PT. Raja Grafindo Persada.

Kriswanto, Erwin Setyo. (2015). Pencak Silat. Yogyakarta: Pustakabarupress.

Lubis, Johansyah dan Wardoyo, Hendro. 2014. Pencak Silat Edisi Kedua. Jakarta: Raja Grafindo. JMP Online Vol. 4 No. 3 Maret (2020) 99-113

Ludyanti, L.N. 2019. Perilaku Kurang Gerak (Sedentary Behaviour) Dengan Perkembangan Psikososial Anak Pra Sekolah. Journal Ilmiah Kesehatan, 7(2):22-31

Muktiani, N. R. (2008). Aplikasi Teknologi Pembelajaran Dalam Mengatasi Permasalahan Pembelajaran Mata Kuliah Pencak Silat. JurnalPJOK Indonesia, 5(1), 24.

Muktiani, N. R. (2014). Identifikasi Kesulitan Belajar Dasar Gerak Pencak Silat Pada Mahasiswa PJKR BersubsidiDiFIK UNY.Jurnal PJOK Indonesia.10(1).

Mulyana. 2013. Pendidikan Pencak Silat. Bandung: PT. Remaja Rosdakarya.

Naharsari, Dyah Nur. 2008. Olahraga Pencak Silat. Jakarta: Ganeca Exact. JMP Online Vol. 4 No. 3 Maret (2020) 99-113

Nasution.(2008). Asas-asas kurikulum.Jakarta: Bumi Aksara

Nugroho, Agung. (2005).Skripsi: Identifikasi Skor Prestasi Teknik Pencak Silat Pada Katagori Tanding. Yogyakarta: FKIP Universitas Negeri Yogyakarta.

Peraturan Pemerintah Republik Indonesia Nomor 20 Tahun 2015 tentang Praktik Akuntan Publik. 2015. Jakarta : SekretariatNegara RI.

Purbodjati. (2008). Pencak Silat Membentuk Kualitas Manusia Indonesia Berkarakter Jati Diri Bangsa. Program Studi Ilmu Keolahragaan Jurusan Pendidikan Kesehatan \& Rekreasi Universitas Negeri Surabaya.

Rosdiani, D. (2014). Perencanaan Pembelajaran Dalam PJOK Dan Kesehatan. Bandung: Alfabeta.

Sandhi, D.T dan Budiwanto, S. (2016). Perbedaan Pengaruh Latihan Menggiring Bola Menggunakan Model Latihan Variasi dan Pengaruh Latihan Reguler Terhadap Teknik Menggiring Bola Pada Anak Latihan Sekolah Sepak Bola Pabrik Gula Ngaderijo Kediri Usia 14 Tahun. Jurnal Kepelatihan Olahraga, Vol 1 No 1

Saputro, G. E., Hanief, Y. N., Herpandika, R. P., \& Saputro, D. P. (2018). Modul tutorial sebagai media pembelajaran pencak silat untuk siswa sekolah menengah kejuruan. Jurnal Keolahragaan, 6(2), 130-138. https://doi.org/10.21831/jk.v0i0.21099.

Setyoadi, Rini, Ika Setyo, Novitasari, T. 2015. Hubungan Penggunaan Waktu Perilaku Kurang Gerak (Sedentary Behaviour) Dengan Obesitas Pada Anak Usia 9-11 Tahun diSD Negrei Beji 02 Kabupaten Tulunggung. Jurnal Ilmu Keperawatan,3(2).

Steve Stork dan Stephen W. Sanders.(2008). Physical Education In Early Childhood. The Elementary School Journal, Vol. 108, No. 3 , pp. 197-199.

Subagyo. 2012. Pencak Silat. Surabaya: Unesa University Press.

Subroto, T., Yudiana,Y., \& Hidayat, Y. (2016). Penulisan Penelitian Tindakan Kelas Dalam PJOK, Olahraga dan Kesehatan. Bandung: FPOK UPI

Sugihartono.(2007). Psikologi pendidikan. Yogyakarta: UNY Press

Sugiyono (2016) Metode Penelitian Pendidikan. Bandung: ALFABETA. 